\title{
Ovarian cycle stage critically affects $21-$ gene recurrence scores in Mmtv-Pymt mouse mammary tumours
}

Sarah M. Bernhardt ${ }^{1,2}$, Pallave Dasari, ${ }^{1,2}$, Danielle J. Glynn ${ }^{1,2}$, Lucy Woolford ${ }^{3}$, Lachlan M. Moldenhauer ${ }^{2,4}$, David Walsh ${ }^{1}$, Amanda R. Townsend ${ }^{4,5}$, Timothy J. Price ${ }^{4,5}$ and Wendy V. Ingman 1,2*

\begin{abstract}
Background: The Oncotype DX 21-gene Recurrence Score is predictive of adjuvant chemotherapy benefit for women with early-stage, estrogen receptor (ER)-positive, HER2-negative breast cancer. In premenopausal women, fluctuations in estrogen and progesterone during the menstrual cycle impact gene expression in hormoneresponsive cancers. However, the extent to which menstrual cycling affects the Oncotype DX 21-gene signature remains unclear. Here, we investigate the impact of ovarian cycle stage on the 21-gene signature using a naturally cycling mouse model of breast cancer.
\end{abstract}

Methods: ER-positive mammary tumours were dissected from naturally cycling Mmtv-Pymt mice at either the estrus or diestrus phase of the ovarian cycle. The Oncotype DX 21-gene signature was assessed through quantitative real time-PCR, and a 21-gene experimental recurrence score analogous to the Oncotype DX Recurrence Score was calculated.

Results: Tumours collected at diestrus exhibited significant differences in expression of 6 Oncotype DX signature genes (Ki67, Ccnb1, Esr1, Erbb2, Grb7, Bag1; $p \leq 0.05)$ and a significant increase in 21-gene recurrence score (21.8 \pm 2.4; mean \pm SEM) compared to tumours dissected at estrus (15.5 $\pm 1.9 ; p=0.03)$. Clustering analysis revealed a subgroup of tumours collected at diestrus characterised by increased expression of proliferation- $(p<0.001)$ and invasion-group $(p=0.01)$ genes, and increased 21 -gene recurrence score $(p=0.01)$. No correlation between $\mathrm{ER}$, $\mathrm{PR}$, HER2, and KI67 protein abundance measured by Western blot and abundance of mRNA for the corresponding gene was observed, suggesting that gene expression is more susceptible to hormone-induced fluctuation compared to protein expression.

Conclusions: Ovarian cycle stage at the time of tissue collection critically affects the 21-gene signature in MmtvPymt murine mammary tumours. Further studies are required to determine whether Oncotype DX Recurrence Scores in women are similarly affected by menstrual cycle stage.

Keywords: Premenopausal Breast cancer, Predictive biomarkers, Ovarian cycle, Genomics, Mouse models

\footnotetext{
* Correspondence: wendy.ingman@adelaide.edu.au

'Discipline of Surgery, Adelaide Medical School, University of Adelaide, The Queen Elizabeth Hospital, Adelaide, 28 Woodville Rd, Woodville 5011,

Australia

${ }^{2}$ Robinson Research Institute, University of Adelaide, Adelaide, Australia

Full list of author information is available at the end of the article
}

(c) The Author(s). 2021 Open Access This article is licensed under a Creative Commons Attribution 4.0 International License, which permits use, sharing, adaptation, distribution and reproduction in any medium or format, as long as you give appropriate credit to the original author(s) and the source, provide a link to the Creative Commons licence, and indicate if changes were made. The images or other third party material in this article are included in the article's Creative Commons licence, unless indicated otherwise in a credit line to the material. If material is not included in the article's Creative Commons licence and your intended use is not permitted by statutory regulation or exceeds the permitted use, you will need to obtain permission directly from the copyright holder. To view a copy of this licence, visit http://creativecommons.org/licenses/by/4.0/ The Creative Commons Public Domain Dedication waiver (http://creativecommons.org/publicdomain/zero/1.0/) applies to the data made available in this article, unless otherwise stated in a credit line to the data. 


\section{Introduction}

The Oncotype DX 21-gene Recurrence Score assay is used in clinical practice for guiding adjuvant chemotherapy treatment decisions for women with early-stage, estrogen receptor (ER)-positive, HER2-negative breast cancer [1-4]. The Oncotype DX assay quantifies the expression of 16 genes associated with proliferation (MKI67, STK15, BIRC5, CCNB1, MYBL2), estrogen signalling (ESR1, PGR, BCL2, SCUBE2), HER2 (ERBB2, GRB7), invasion (MMP11, CSTV) and other genes (GSTM1, BAG1, CD68), as well as 5 house-keeping genes. These 21 signature genes are combined in an algorithm to calculate a Recurrence Score that reflects the patient's underlying risk of disease recurrence and predicts the likely benefit from the addition of chemotherapy to endocrine treatment [5-10]. The Oncotype DX assay guides chemotherapy treatment decisions for both premenopausal and postmenopausal breast cancer patients [11], however it was developed predominantly in postmenopausal women [12]. Differences in chemotherapy benefit between young women with intermediate Recurrence Scores compared to older women has recently been described [10]. Moreover, a recent study has demonstrated that results generated by the Oncotype DX 21-gene algorithm are affected by patient age at the time of tissue collection [13]. Together, these observations suggest that the algorithm is affected by underlying differences in tumour biology in premenopausal women that are yet to be defined.

Menstrual cycling in younger premenopausal women could affect the accuracy of the Oncotype DX algorithm. In premenopausal women, ER-positive breast cancers are highly responsive to fluctuations in ovarian hormones that occur across the menstrual cycle. Breast cancer biopsies collected from women during the luteal phase of the menstrual cycle exhibit increased proliferation compared to paired biopsies collected during the follicular phase [14]. Similarly, growth factor receptor expression is increased at the luteal phase of the menstrual cycle, when circulating concentrations of progesterone peak [15]. Expression of a number of Oncotype DX signature genes also varies with menstrual cycle stage, including the estrogen-regulated $P G R$ gene and proliferation-associated genes MKI67, CCNB1, BIRC5, and MYBL2 [16-18]. Evidence that hormone-induced gene expression changes could impact the Oncotype DX gene signature comes from in vitro findings that estrogen and progesterone co-treatment of a breast cancer cell line increases Oncotype DX Recurrence Score compared to estrogen treatment alone [19]. However, despite the known effects of ovarian hormones on breast cancer gene expression, whether menstrual cycling in premenopausal breast cancer patients affects the Oncotype DX Recurrence Score has not been directly addressed. A key limitation in advancing this issue is the lack of availability of large human breast cancer datasets with matched clinical information on menstrual cycle stage [20]. To partially address this limitation, animal models can provide early evidence to precede large-scale clinical studies.

Transgenic mice harbouring the polyomavirus middle $\mathrm{T}$-antigen oncogene driven by the mammary gland specific mouse mammary tumour virus promoter (MmtvPymt) exhibit well-defined histopathological features and biomarkers with direct relevance to Oncotype DX. In Mmtv-Pymt mice, tumour progression to malignancy occurs in a number of stages that are comparable to human disease progression from in situ lesions to invasive carcinoma [21]. Mmtv-Pymt tumours express ER and PR in the earlier stages of tumour development and are responsive to endocrine treatment [21, 22]. As tumours progress to become more aggressive and metastatic, Erbb2 and Ccnd1 increase in expression [21]. Biomarkers $M k i 67$ and $B c l 2$ are also associated with tumour progression in the Mmtv-Pymt model [23]. Use of the Mmtv-Pymt model in pre-clinical studies was instrumental in establishing the role of macrophages in breast cancer progression [24], with macrophage-specific CD68 now recognised as a promising prognostic and predictive biomarker [25, 26] which is included in the Oncotype DX signature. Thus, Mmtv-Pymt transgenic mice are an ideal model to investigate the impact of ovarian cycling on Oncotype DX Recurrence Scores as mammary tumours express many Oncotype DX signature genes that have been demonstrated to be associated with disease progression.

In this study, we investigate the impact of ovarian cycle stage on the Oncotype DX 21-gene signature in mammary tumours from naturally cycling Mmtv-Pymt mice. Mammary tumours were dissected from MmtvPymt transgenic mice at either the estrus or diestrus phase of the ovarian cycle. These two phases of the cycle were used as estrus phase has been shown previously to exhibit high estradiol and low progesterone and diestrus phase exhibits moderate estradiol and high progesterone, comparable to the follicular and luteal phase of the human menstrual cycle respectively [27, 28]. ER-positivity was confirmed by immunohistochemistry. The Oncotype DX 21-gene signature was assessed through quantitative real time-PCR, and 21-gene experimental recurrence scores analogous to the Oncotype DX platform were calculated [5]. Results from this study show that ovarian cycle stage affects expression of the 21-gene signature and experimental recurrence scores in Mmtv-Pymt mammary tumours. Mammary tumours dissected from mice at diestrus exhibit increased expression of proliferative and HER2-associated genes, and increased 21-gene experimental recurrence scores, compared to tumours 
dissected at estrus. Furthermore, clustering analysis identified a subset of tumours collected at diestrus that may be more sensitive to hormonal fluctuations during the ovarian cycle, and more prone to cycle-induced changes in recurrence scores. This study provides preclinical evidence that menstrual cycling might affect Oncotype DX Recurrence Scores in premenopausal women.

\section{Methods}

\section{Mmtv-Pymt transgenic mice}

Ethics approval was obtained from The University of Adelaide Animal Ethics Committee (Approval number M2016-124) and all experiments were performed in accordance with the Australian Code of Practice for the Care and use of Animals for Scientific Purposes. All mice were maintained in pathogen-free conditions with 12:12 light-dark cycles and controlled temperature. All methods are reported in accordance with ARRIVE guidelines (https://arriveguidelines.org).

Transgenic mice harbouring the polyomavirus middle T-antigen oncogene (Pymt) driven by the mammary gland specific mouse mammary tumour virus promoter (Mmtv; Mmtv-Pymt) were used to model the effect of ovarian cycle stage on the 21-gene signature. Tumours from Mmtv-Pymt mice are ER-positive in the early stage of development and progress to become ER-negative [21]. Immunohistochemistry were performed to confirm that tumours were estrogen receptor (ER)-positive.

For inclusion in the study it was required that mice exhibited normal estrous cycles, defined as 4 to 5 days between one estrus phase and the next estrus phase. To assess this, once tumours were palpable estrous cycles were tracked by daily vaginal smearing for at least 2 complete cycles prior to tissue collection, as previously described $[28,29]$. Mice were randomly assigned to be euthanised at either the estrus or diestrus phase of the estrous cycle.

Mice were euthanised by cardiac puncture under deep anaesthesia $(500 \mu \mathrm{l}$ of $2 \%$ Avertin (Sigma-Aldrich) injected intraperitoneally) followed by cervical dislocation at either the estrus or diestrus stage of the estrous cycle, and mammary tumours dissected. The primary tumour was cut in half. Half the tumour was fixed in $4 \%$ paraformaldehyde overnight at $4{ }^{\circ} \mathrm{C}$, washed thrice with $1 \times \mathrm{PBS}$, and stored in $70 \%$ ethanol prior to processing and embedding in paraffin wax. The other half of the tumour was immediately snap-frozen in liquid nitrogen and stored at $-80{ }^{\circ} \mathrm{C}$ until RNA extraction was performed.

\section{Haematoxylin eosin staining}

Haematoxylin and eosin (H\&E) staining was performed on $5 \mathrm{uM}$ paraffin-embedded sections. Sections were dewaxed in xylene, passed sequentially through 100, 90, 70 and $50 \%$ ethanol for rehydration. The sections were then stained with haematoxylin and counterstained with eosin, prior to dehydrating and mounting with Entellan mounting medium. H\&E stains of primary mammary tumours dissected from Mmtv-Pymt mice were assessed by a veterinary pathologist blind to mouse estrous cycle phase, to confirm that tumour tissue were of mammary epithelial cell origin, and to grade tumours.

\section{Microscopy}

Tissue sections stained by immunohistochemistry or H\&E were captured as a digital image using a Nanozoomer 1.0 (Hamamatsu, Shizouka, Japan) digital imager at a zoom equivalent to a $40 \mathrm{x}$ objective lens. All microscopy images are shown as they were captured, and have not been adjusted (ie brightness/contrast, colour, resolution, processing, averaging or sharpen/soften) in any way.

\section{RNA extraction and complementary DNA (cDNA) synthesis}

Total RNA was extracted from snap-frozen mammary tumours using TRIzol (Life technologies). Samples were treated with TURBO DNA-free DNase kit (Life Technologies) to remove genomic DNA contamination. cDNA was reverse transcribed from $500 \mathrm{ng}$ of RNA using iScript cDNA synthesis kit (Bio-Rad), with reactions incubated at $25^{\circ} \mathrm{C}$ for $5 \mathrm{~min}, 42^{\circ} \mathrm{C}$ for $25 \mathrm{~min}$, and $85^{\circ} \mathrm{C}$ for $5 \mathrm{~min}$.

\section{Quantitative real time-PCR}

Real time-PCR amplification was performed on a BioRad CFX384 Real-Time Detection System using SYBR Green PCR Master Mix (Bio-Rad). Reactions were loaded into 384-well plates in triplicate, using a QIAgility robot (Qiagen). PCR conditions were $95^{\circ} \mathrm{C}$ for 10 min, then 50 cycles of $95^{\circ} \mathrm{C}$ for $15 \mathrm{~s}, 60^{\circ} \mathrm{C}$ for $15 \mathrm{~s}, 72^{\circ} \mathrm{C}$ for $30 \mathrm{~s}$.

The 21-gene signature was assessed through quantitative real time-PCR. Primer pairs are detailed in Table 1. A 21-gene experimental recurrence score analogous to the Oncotype DX Recurrence Score was calculated using the Oncotype DX Recurrence Score algorithm.

\section{Calculation of 21-gene experimental recurrence scores} Normalised gene expression measurements were calculated as $\Delta \mathrm{CT}=\mathrm{CT}$ (mean of five reference genes) $-\mathrm{CT}$ (gene of interest) +10 . A 1-unit increase in referencenormalised expression measurements reflects a doubling of RNA. Experimental recurrence scores were calculated from reference-normalised gene expression, using the Oncotype DX 21-gene Recurrence Score algorithm, as previously described [13]. 
Table 1 PCR primers used to quantify gene expression in Mmtv-Pymt murine mammary tumours. Primers recognise mouse genes

\begin{tabular}{|c|c|c|}
\hline Gene & Primer sequence & Product length (bp) \\
\hline Mki67 & $\begin{array}{l}\text { 5' - AATCCAACTCAAGTAAACGGGG } \\
3^{\prime} \text { - TTGGCTTGCTTCCATCCTCA }\end{array}$ & 127 \\
\hline Stk15 & $\begin{array}{l}\text { 5' - CTGGATGCTGCAAACGGATAG } \\
\text { 3' - CGAAGGGAACAGTGGTCTTAACA }\end{array}$ & 105 \\
\hline Birc5 & $\begin{array}{l}\text { 5' - CTACCGAGAACGAGCCTGATT } \\
\text { 3' - AGCCTTCCAATTCCTTAAAGCAG }\end{array}$ & 60 \\
\hline Ccnb1 & $\begin{array}{l}\text { 5' - AGAGCTATCCTCATTGACTGGC } \\
\text { 3' - AACATGGCCGTTACACCGAC }\end{array}$ & 155 \\
\hline Mybl2 & $\begin{array}{l}\text { 5' - GTGAGGCAGTTTGGACAGCAA } \\
\text { 3' - GGATTCAAAACCCTCAGCCA }\end{array}$ & 101 \\
\hline Esr1 & $\begin{array}{l}\text { 5' - TGATTGGTCTCGTCTGGCGCT } \\
\text { 3' - GCACACAAACTCTTCTCCCTGC }\end{array}$ & 179 \\
\hline Pgr & $\begin{array}{l}\text { 5' - CGCCATCTACCAGCCGCTC } \\
\text { 3' - TGAATCTGGCCTCAGGTAGTT }\end{array}$ & 121 \\
\hline $\mathrm{BCl} 2$ & $\begin{array}{l}\text { 5' - ATGCCTITGTGGAACTATATGGC } \\
\text { 3' - GGTATGCACCCAGAGTGATGC }\end{array}$ & 120 \\
\hline Scube2 & $\begin{array}{l}\text { 5' - GGCTGTGTCCACGACTGTTAA } \\
\text { 3' - GTTCTCCAAGCATTCGTCCAT }\end{array}$ & 117 \\
\hline Erbb2 & $\begin{array}{l}\text { 5' - TGCTCAACTGGTGTGTTCAGATT } \\
3^{\prime} \text { - TTCGGGCAGCTAGGTCC }\end{array}$ & 84 \\
\hline Grb7 & $\begin{array}{l}\text { 5' - ACAAACAGGCATATCCCATGAAG } \\
\text { 3' - TAGAGGCCAGATCGACGCA }\end{array}$ & 159 \\
\hline Mmp11 & $\begin{array}{l}\text { 5' - GCCTGATGTACTGAATGCCC } \\
\text { 3' - GCTCCCTTACAAGCTGCCA }\end{array}$ & 119 \\
\hline Ctsv & $\begin{array}{l}\text { 5' - ATCAAACCTITAGTGCAGAGTGG } \\
\text { 3' - CTGTATTCCCCGTTGTGTAGC }\end{array}$ & 136 \\
\hline Gstm1 & $\begin{array}{l}\text { 5' - ATACTGGGATACTGGAACGTCC } \\
\text { 3' - AGTCAGGGTTGTAACAGAGCAT }\end{array}$ & 349 \\
\hline Cd68 & $\begin{array}{l}\text { 5' - TGTCTGATCTTGCTAGGACCG } \\
\text { 3' - GAGAGTAACGGCCTIITTGTGA }\end{array}$ & 75 \\
\hline Bag1 & $\begin{array}{l}\text { 5' - GCAGCAGGGAGTTGACTAGAA } \\
\text { 3' - TTACTTCCTCGGTTTGGTCG }\end{array}$ & 111 \\
\hline Actb & $\begin{array}{l}\text { 5' - GTGTGACGTTGACATCCGTAAAG } \\
\text { 3' - CTCAGGAGGAGCAATGATCTTGAT }\end{array}$ & 151 \\
\hline Gapdh & $\begin{array}{l}\text { 5' - ACACATTGGGGGTAGGAACA } \\
3^{\prime} \text { - AACTITGGCATTGTGGAAGG }\end{array}$ & 223 \\
\hline Rplp0 & $\begin{array}{l}\text { 5' - AGATTCGGGATATGCTGTTGGC } \\
\text { 3' - TCGGGTCCTAGACCAGTGTTC }\end{array}$ & 109 \\
\hline Gusb & $\begin{array}{l}\text { 5' - CGGGCTGGTGACCTACTGGATT } \\
\text { 3' - TGGCACTGGGAACCTGAAGT }\end{array}$ & 134 \\
\hline Tfre & $\begin{array}{l}\text { 5' - GTTTCTGCCAGCCCCTTATTAT } \\
\text { 3' - GCAAGGAAAGGATATGCAGCA }\end{array}$ & 152 \\
\hline
\end{tabular}

\section{Protein extraction and Western blot analysis}

Total protein was extracted from snap-frozen mammary tumours using Triton X-100 lysis buffer $(50 \mathrm{mM}$ Tris pH 8.0, $150 \mathrm{mM}$ sodium chloride, $1 \%$ Triton X-100, protease inhibitor cocktail (Roche)). Samples were quantified using Bradford Protein Assay (ThermoFisher), and $20 \mu \mathrm{g}$ of protein was separated on a $12 \%$ precast polyacrylamide gel (BioRad) at $30 \mathrm{~mA}$ for $40 \mathrm{~min}$. Proteins were transferred onto a nitrocellulose membrane using Trans-Blot Turbo Transfer Packs (BioRad) in a TransBlot Turbo Transfer chamber system (BioRad). Membranes were blocked with $5 \% \mathrm{w} / \mathrm{v}$ skim milk in TBS-T (50 mM Tris-Cl pH 7.5, $50 \mathrm{mM} \mathrm{NaCl,} \mathrm{0.2 \%} \mathrm{Tween-20)}$ for $1 \mathrm{~h}$ at room temperature, prior to incubation with primary antibodies for $1 \mathrm{~h}$ at room temperature. Primary antibodies were anti-ER (Santa Cruz, 1:500), anti-PR (Santa Cruz, 1:500), anti-HER2 (Cell Signalling Technologies, 1:500), anti-Ki67 (Abcam, 1:500) and antißactin (Abcam, 1:1000). Membranes were then washed thrice with TBS-T, prior to incubation with appropriate anti-mouse (Dako, 1:2000) or anti-rabbit (Dako, 1:2000) antibodies for $30 \mathrm{~min}$ at room temperature. Membranes were exposed using enhanced chemiluminescence (ECL; BioRad) and visualised using a Fuji LAS4000 Luminescent Image Analyser. To re-probe, membranes were first stripped using a low $\mathrm{pH}$ glycine stripping buffer $(1.5 \%$ glycine $\mathrm{pH} 2.2,0.1 \%$ SDS, $1 \%$ Tween) for $10 \mathrm{~min}$ at room temperature, prior to re-blocking and subsequent reprobing with primary antibodies as described above. All western blot images are shown as they were imaged, and have not been adjusted (ie brightness/contrast, colour, resolution, processing, averaging or sharpen/soften) in any way.

\section{Statistical analyses}

All data were assessed using SPSS Statistics Version 24 (IBM Corporation, Armonk, NY, USA) or SAS 9.4 (SAS Institute Inc., Cary, NC, USA). Gene expression and 21gene experimental recurrence scores were compared between ovarian cycle stages using independent T-tests. Differences in gene expression and 21-gene experimental recurrence scores between clusters were assessed using one-way analysis of variance with post hoc comparisons performed. Correlation between mRNA and protein expression was assessed using Spearman's rank correlation coefficient. Data were considered significant when $p \leq$ 0.05 .

\section{Results \\ Assessment of tumour clinical features for inclusion in study}

Hematoxylin and eosin stains were performed on primary tumours collected from a total of 60 mice, and tumours were assessed and graded by a veterinary pathologist. Tumours were included in the study if tumour tissue were of mammary epithelial cell origin. Examples of hematoxylin and eosin stained mammary tumours are presented in Fig. 1A-C and Supplementary figures 1, 2 and 3. Mammary tumours were also assessed for ER positivity through immunohistochemistry. All tumours stained positive for ER. An example of ER staining is presented in Fig. 1D and Supplementary figure 4. 

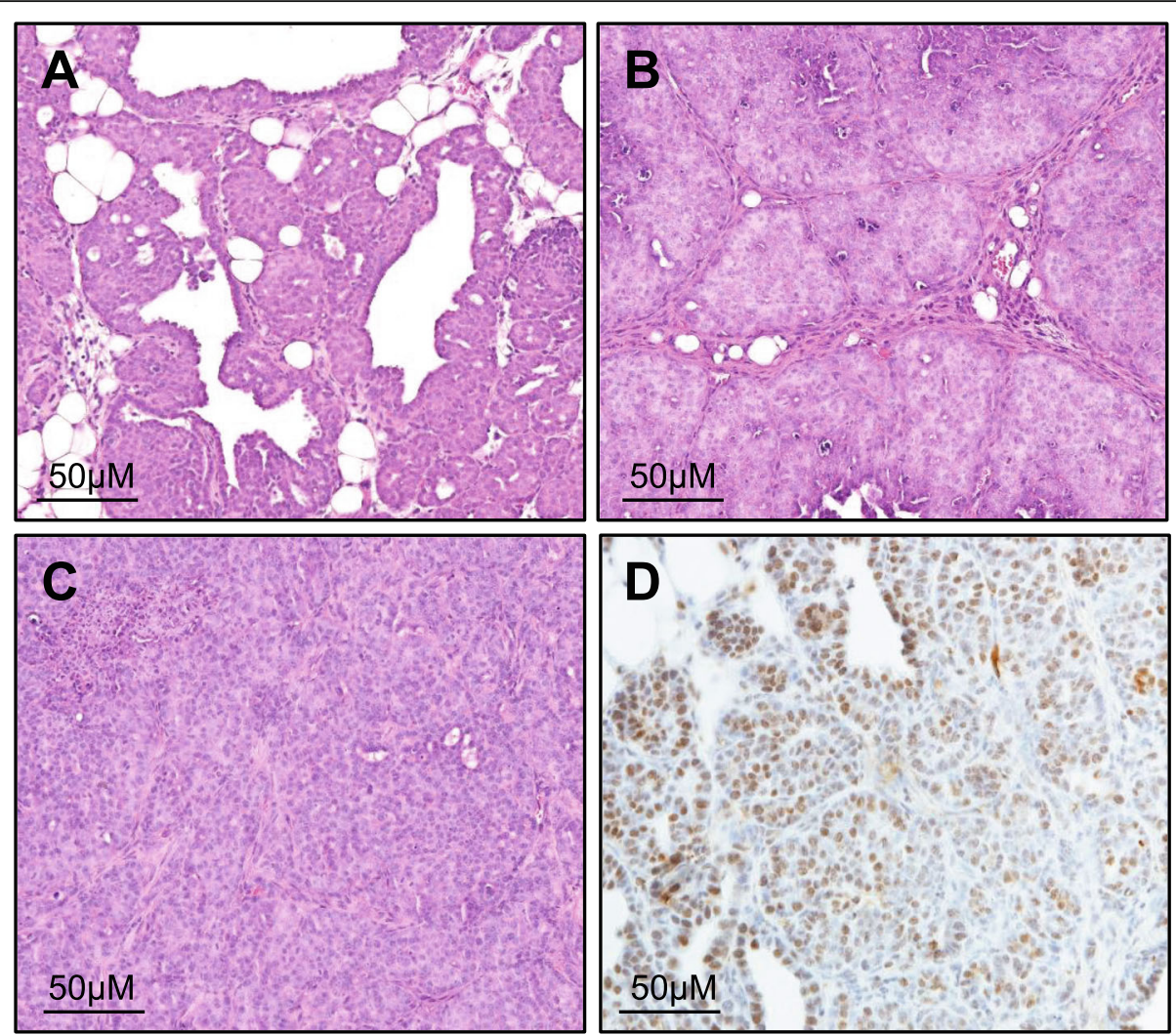

Fig. 1 Histological and immunohistochemical analysis of Mmtv-Pymt mammary tumours. Representative images of haematoxylin and eosin stained Mmtv-Pymt mammary tumours of different grades. Tumours were assessed and graded by a veterinary pathologist. A grade 2, B grade 3, and $\mathbf{C}$ grade 4 tumours. D Representative images of estrogen receptor staining in Mmtv-Pymt mammary tumours. Bars represent $50 \mu \mathrm{M}$

Table 2 Clinical features of primary mammary tumours collected from Mmtv-Pymt mice that met the inclusion criteria for the study. Mammary tumours were collected from Mmtv-Pymt transgenic mice at either estrus or diestrus phase of the ovarian cycle. Ovarian cycle stage was determined by cytological analysis of vaginal smears, performed for at least 2 weeks. All tumours are estrogen receptor positive as determined through immunohistochemistry. No differences in tumour features were observed between ovarian cycle stages

\begin{tabular}{lll}
\hline Characteristics & Estrus $\mathbf{n}(\%)$ & Diestrus $\mathbf{n}(\%)$ \\
\hline Total Number & 25 & 28 \\
Mouse age (Days; range) & $78(50-101)$ & $75(43-96)$ \\
Mouse Body Weight (Grams; range) & $23.5(17.0-27.4)$ & $24.3(19.3-30.8)$ \\
Tumour Latency (Days; range) & $54.2(20-89)$ & $47.0(33-85)$ \\
Tumour Size & & $6(21)$ \\
$\quad<10 \mathrm{~mm}$ & $6(24)$ & $10(36)$ \\
$10-15 \mathrm{~mm}$ & $9(36)$ & $7(25)$ \\
$16-20 \mathrm{~mm}$ & $8(32)$ & $5(18)$ \\
$\quad>20 \mathrm{~mm}$ & $2(8)$ & $449.6(93.7-1366.3)$ \\
Tumour Weight (Milligrams; range) & $469.8(95.1-953.9)$ & $2(7)$ \\
Tumour Grade & & $7(25)$ \\
2 & $4(16)$ & $19(68)$ \\
\hline
\end{tabular}


Of the 60 mice in the study, 1 mouse was excluded from analysis as the tumour was salivary gland epithelial cell in origin. Two mice were excluded from analysis as smearing was performed for less than 2 full cycles. These mice were culled for ethical reasons before 2 cycles could be tracked, as the primary tumour size exceeded the maximum $2000 \mathrm{~mm}^{3}$ tumour burden threshold. A further 4 mice were excluded from analysis as they were not cycling normally. A total of 53 mice were included in analysis (estrus $n=25$; diestrus $n=28$ ). Tumour and mouse characteristics are presented in Table 2.

The effect of ovarian cycle stage on the 21-gene signature in ER-positive mouse mammary tumours

To determine whether ovarian cycling affects the 21gene signature, gene expression was assessed through quantitative real time-PCR and compared between tumours collected at estrus and diestrus phases of the ovarian cycle. Expression of 6 Oncotype DX signature genes were differentially expressed. Tumours collected from mice at diestrus exhibited a significant increase in the expression of genes Mki67 ( $p=0.05)$, Ccnb1 ( $p=$ $0.02), \operatorname{Erbb2}(p=0.03), \operatorname{Grb7}(p=0.02)$, and Bag1 ( $p=$ $0.05)$, compared to tumours collected at estrus. Conversely, expression of Esr1 ( $p=0.02$ ) was significantly reduced in tumours collected at diestrus compared to estrus (Fig. 2).

We next sought to determine how changes in the 21gene signature with ovarian cycle stage impact experimental recurrence scores. Using reference-normalised gene expression, 21-gene experimental recurrence scores were calculated for each tumour. This recurrence score is analogous to the Oncotype DX Recurrence Score. Tumours collected from mice at diestrus show a significant increase in experimental recurrence score $(21.8 \pm 2.4$; mean \pm SEM) compared to tumours collected at estrus $(15.5 \pm 1.9 ; p=0.039$; Fig. 3).

The effect of ovarian cycle stage on clustering analysis of ER-positive mouse mammary tumours

To further investigate how ovarian cycling affects the gene expression profile, $t$-Distributed Stochastic
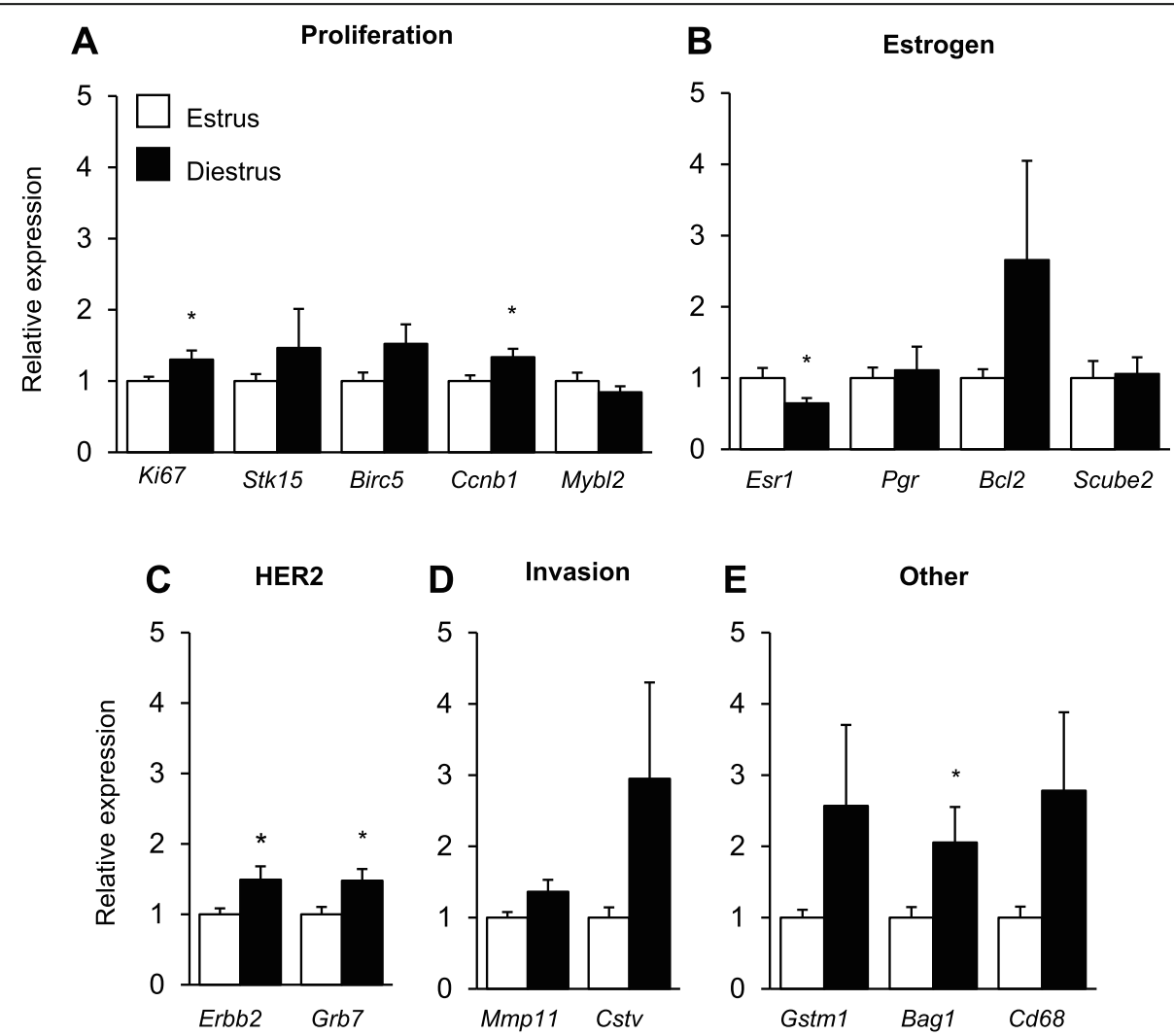

Fig. 2 The effect of ovarian cycle stage on the 21-gene signature. Mammary tumours were collected from mice at either the estrus $(n=25)$ or diestrus $(n=28)$ phase of the ovarian cycle. Expression of the genes included in the 21-gene signature were measured by real-time PCR; including (A) 5 Proliferation (Ki67, Stk15, Birc5, Ccnb1, Mybl2); B 4 Estrogen (Esr1, Pgr, Bcl2, Scube2); C 2 HER2 (Erbb2, Grb7); D 2 Invasion (Mmp11, CstV); and (E) 3 Other (Gstm1, Bag1, Cd68) group genes. Gene expression was normalised to the average of 5 reference genes (Actb, Gapdh, Rplp0, Gus, Tfrc). Results are presented relative to tumours collected at estrus. All data are presented as mean + SEM. Statistical significance was determined when $p \leq 0.05$ using independent t-tests. * signifies $p \leq 0.05$ 


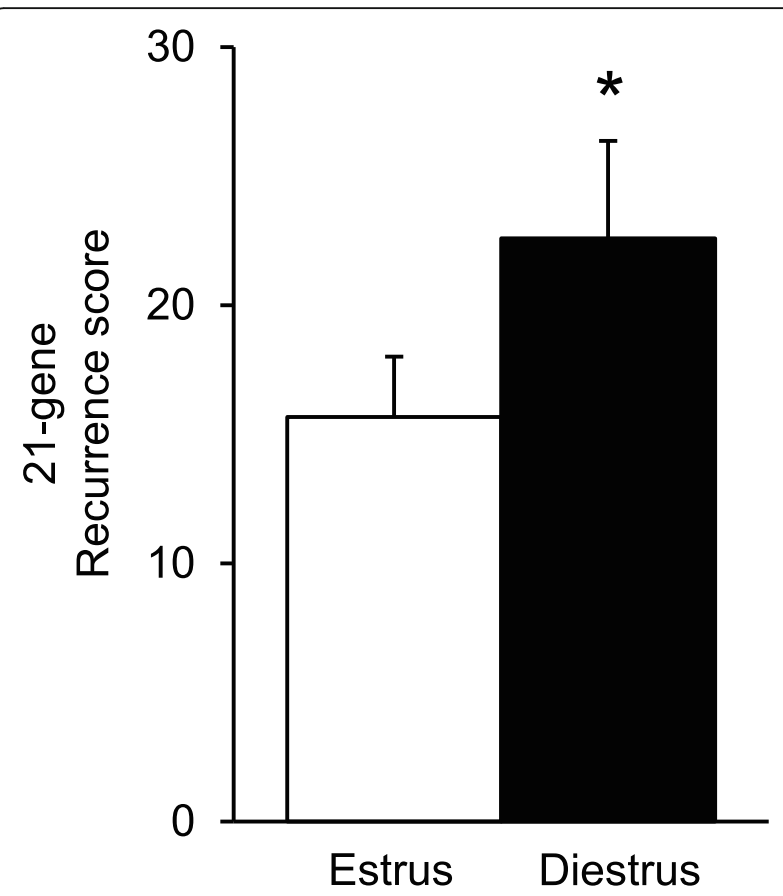

Fig. 3 The effect of ovarian cycle stage on 21-gene experimental recurrence scores. Estrogen receptor-positive mammary tumours were collected from Mmtv-Pymt transgenic mice at either the estrus ( $n=25)$ or diestrus ( $n=28$ ) phase of the ovarian cycle. 21-gene recurrence scores were calculated from reference-normalised gene expression as described in the methods. Data are presented as mean + SEM. Statistical significance was determined when $p<0.05$ using Student's t-test. * ${ }^{*}$ ignifies $p<0.05$

Neighbour Embedding (t-SNE) analysis was applied to our gene expression data. The t-SNE technique of dimensionality reduction allows for multi-gene datasets to be visualised in a 2-dimentional plot [30]. Consequently, this allowed us to visualise similarities in gene expression profiles between individual tumours.

Tumours grouped into 4 main clusters (Fig. 4A), each which showed distinct gene expression profiles. To highlight the differences in gene expression between clusters, 21-gene group scores were calculated for each cluster (Fig. 4B-E). Clusters 1 and 2 predominantly correspond to tumours collected at estrus and diestrus phases of the ovarian cycle respectively. These clusters exhibited similarities in expression of Estrogen, Proliferation, and HER2 group genes $(p>0.05)$; with the difference between clusters being driven primary by increased expression of Invasion group genes in Cluster 2, compared to Cluster $1(p=0.005)$. In respect to the remaining clusters, Cluster 1 and Cluster 2 showed reduced expression of Estrogen group genes, compared to Cluster $3(p<$ $0.001, p=0.001$ respectively) and Cluster $4(p=0.001$, $p=0.009$ respectively).

We next compared the average recurrence scores for each cluster. Interestingly, tumours in Cluster 4 showed a significant increase in 21-gene recurrence scores (37.1 \pm 9.5; mean \pm SEM), compared to Cluster 1 (17.1 \pm $2.0 ; p=0.001)$, Cluster $2(19.5 \pm 2.2 ; p=0.004)$, and Cluster $3(20.0 \pm 3.8 ; p=0.014)$ (Fig. $4 \mathrm{~F})$. No other differences in recurrence scores were observed between clusters $(p>0.05)$. The increased recurrence score of Cluster 4 are being driven by an increased expression of Estrogen, Proliferation, and Invasion group genes, as compared to Cluster 1 ( $p=0.001, p<0.001, p=0.006$ respectively), and Cluster 2 ( $p=0.009, p=0.002, p=0.25$ respectively). No differences in gene expression were observed between Cluster 3 and Cluster 4 $(p=0.77, p=0.33, p=$ 0.06 respectively).

\section{The relative effects of ovarian cycle stage on gene expression versus protein expression}

Having found that ovarian cycle stage significantly affects mammary tumour gene expression, we next sought to define how changes in gene biomarker expression translate into changes in protein biomarker expression. In the clinic, the assessment of ER, PR, HER2 and Ki67 protein is the gold standard for informing treatment decisions [1, 3], as their expression predicts the tumours likely response to therapy [31-33]. Therefore, we focused our analysis on assessing concordance between gene and protein expression of ER, PR, HER2 and Ki67.

Secondary mammary tumours were collected from Mmtv-Pymt transgenic mice at either the estrus $(n=21)$ or diestrus $(n=24)$ phase of the ovarian cycle. All tumours were ER and PR-positive, as confirmed by IHC analysis (data not shown). mRNA expression of Esr1, Pgr, Erbb2, and Ki67 was assessed through quantitative real-time PCR. Tumours collected from mice at diestrus showed a significant increase in the expression of Erbb2 compared to tumours collected from mice at estrus $(p=$ 0.03; Fig. 5A). Expression of Ki67 trended to increase, but did not reach significance $(p=0.09)$. No changes in Esr1 $(p=0.79)$ or Pgr $(p=0.17)$ expression were observed (Fig. 5A).

To assess how ovarian cycle stage affects protein biomarker expression, total ER, PR, HER2 and Ki67 protein was assessed through western blot analysis. No significant differences were observed in the expression of any protein biomarkers between tumours collected at estrus, compared to tumours collected at diestrus $(p>0.05$; Fig. 5B). Examples of western blots are presented in Fig. 5C and Supplementary figure 5.

To assess whether changes in gene expression with ovarian cycle stage translate into changes in protein expression, we next assessed concordance between gene and protein expression using Spearman's correlations. We found generally poor correlation between gene expression and protein expression of ER (estrus $r=0.019$, diestrus $r=0.020$, Fig. 5D), PR (estrus $r=0.0006$, diestrus 

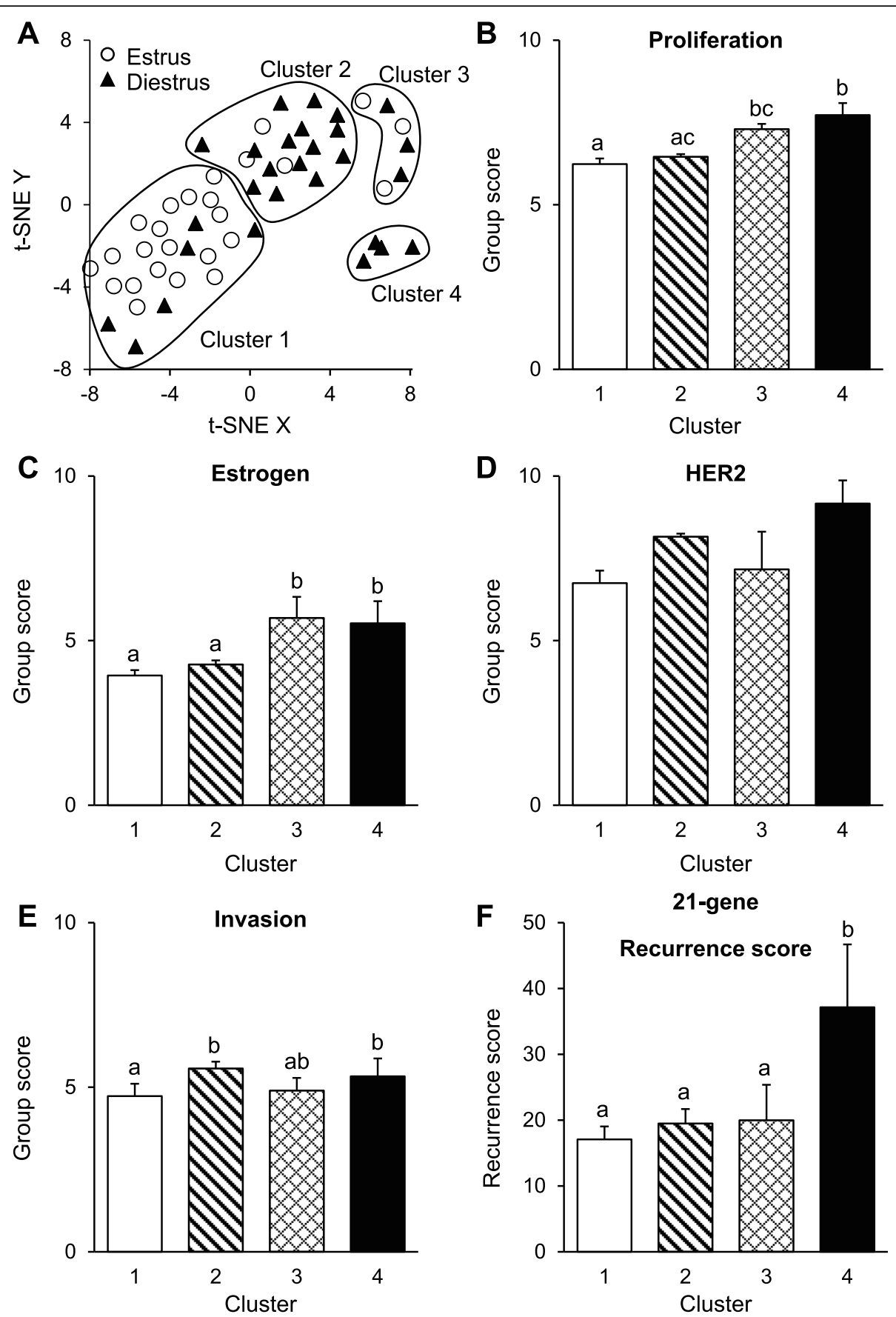

Fig. 4 Clustering of mammary tumours based on similarities in gene expression profiles. Mammary tumours were collected from naturally cycling Mmtv-Pymt mice at either estrus $(n=25)$ or diestrus $(n=28)$ stages of the ovarian cycle. A Mammary tumours were clustered using t-Distributed Stochastic Neighbour Embedding (t-SNE) analysis. Each cluster was characterised by a unique gene expression signature. 21-gene group scores were calculated for each cluster, as described in the methods. Presented are the average group scores for each cluster: B Proliferation group, $\mathbf{C}$ Estrogen group, $\mathbf{D}$ HER2 group, and $\mathbf{E}$ Invasion group. $\mathbf{F}$ The average 21-gene experimental recurrence score for each cluster. All results are presented as mean + SEM. Significance was assessed using one-way analysis of variance with post hoc comparisons performed. Different letters indicate statistical significance $(p \leq 0.05)$ between groups 


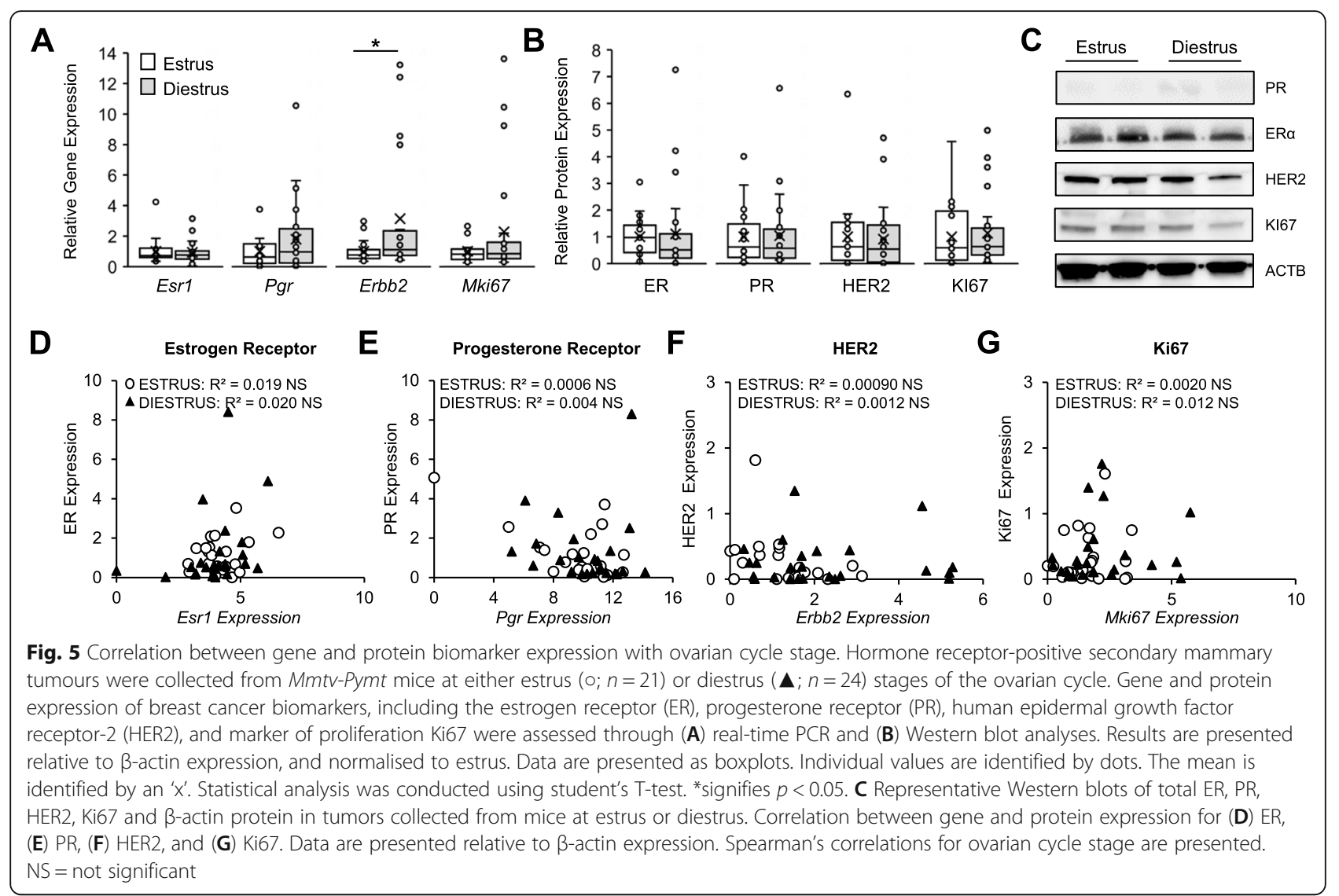

$r=0.004$, Fig. 5E), HER2 (estrus $r=0.00090$, diestrus $r=0.0012$, Fig. 5F), and Ki67 (estrus $r=0.0020$, diestrus $r=0.012$, Fig. 5G).

\section{Discussion}

Ovarian cycling critically affects the 21-gene signature and experimental recurrence scores in ER-positive mouse mammary tumours

The Oncotype DX 21-gene Recurrence Score is predictive of adjuvant chemotherapy benefit for women with earlystage, hormone receptor (HR)-positive, HER2-negative breast cancer and is recommended in clinical guidelines for guiding adjuvant chemotherapy treatment decisions. However, the Recurrence Score algorithm was largely developed in postmenopausal women, and it remains unclear whether it is suitable for use in premenopausal women, where fluctuations in estrogen and progesterone during the menstrual cycle affect gene expression.

This study in mice provides pre-clinical evidence that menstrual cycling might affect Oncotype DX Recurrence Scores for premenopausal women. Tumours dissected from mice at diestrus, which is characterised by high concentrations of progesterone and an intermediate estrogen concentration [28,34-36], analogous to the luteal phase in humans, show a significant increase in 21-gene recurrence scores, compared to tumours collected at estrus. Increased expression of Proliferation and HER2 group genes largely contributed to the increased 21-gene recurrence score observed in tumours collected at diestrus. Critically, in premenopausal women, proliferation and HER2 gene expression has been shown to fluctuate across the course of the menstrual cycle. Highest proliferative activity of breast cancer samples are observed during the luteal phase, with increasing concentrations of progesterone [14, 37]. Similarly, HER2 expression peaks during the luteal phase [15]. These findings are consistent with a recent study in women [13] which demonstrated that results generated by the Oncotype DX 21-gene algorithm were critically affected by patient age at the time of tissue collection, and that these agerelated differences were driven by variable expression of proliferation and HER2 group genes.

Taken together, these data suggest that the Oncotype DX 21-gene assay may be less precise for cycling premenopausal women, compared to non-cycling postmenopausal women, as Recurrence Scores may partially depend on the menstrual cycle stage at the time of tissue collection. For premenopausal women, Oncotype DX testing of hormone responsive tumours may produce a higher Recurrence Score for a tumour sampled during the luteal phase of a woman's menstrual cycle, when circulating concentrations of progesterone are high, 
compared to that same breast cancer sampled during the follicular phase, when progesterone is low.

\section{The effects of ovarian cycle stage on 21-gene experimental recurrence scores are limited to a subset of ER-positive tumours}

There is significant inter-tumour and intra-tumour heterogeneity within ER-positive breast tumours, and this contributes to their heterogeneous clinical outcomes, variable response to chemotherapy, and also how these tumours respond to ovarian hormones. Therefore, certain tumours might be more sensitive to fluctuations in circulating concentrations of ovarian hormones during the estrous cycle. Indeed, in mice, we identified a subset of ER-positive tumours collected at diestrus (Cluster 4) that showed a significant increase in 21-gene recurrence scores, compared to the remaining tumour clusters. Tumours in Cluster 4 may be more sensitive to fluctuations in estrogen and progesterone during the ovarian cycle, and consequently, more prone to cycle-induced changes in recurrence scores.

Increased expression of genes downstream of estrogen signalling reflects tumour responsiveness to ovarian hormones. Tumours exhibiting high expression of estrogenregulated genes are more dependent on hormone signalling for growth, and therefore may be more sensitive to fluctuations in estrogen and progesterone during the ovarian cycle. Indeed, Cluster 4, which showed highest 21-gene recurrence scores, also exhibited highest expression of estrogen-regulated genes, consistent with the possibility that these tumours are more sensitive to hormonal fluctuations. Additionally, this cluster was characterised by increased expression of proliferative genes, which have been previously described as being affected by ovarian cycle stage $[17,18]$. We suggest that Cluster 4 is more sensitive to estrogen and progesterone, and an increase in expression of Proliferation-group genes at diestrus is the key driver behind their increased recurrence scores.

Unfortunately, serum concentration of estrogen and progesterone could not be determined in this cohort of mice. Many previous studies have employed a radioimmunoassay (RIA) approach to investigate mouse estradiol and progesterone in serum from naturally cycling mice. The commercial RIA kits DSL-4800 and DSL3400 (Diagnostic Systems Laboratories, Webster,TX, USA) that measure estradiol and progesterone respectively have been well-validated and are considered the industry standard. Unfortunately, these kits have been discontinued, and none of the currently available ELISA kits are validated for serum hormones in naturally cycling mice, and none that we trialled were found to be specific for estradiol or progesterone (data not shown).
It is possible that for a majority of ER-positive tumours, ovarian cycle stage does not affect recurrence scores. However, the underlying tumour biology that drives an increased sensitivity to cycle-induced changes remains unclear. Furthermore, while we report that the ovarian cycle stage can impact 21-gene experimental recurrence scores, the cycle stage and hormonal environment that reflects the true tumour biology and the likely response from adjuvant chemotherapy is not known.

\section{The effects of ovarian cycle stage are likely more pronounced on gene expression versus protein expression}

Although we found that ovarian cycle stage significantly affects gene biomarker expression in murine mammary tumours, protein biomarker expression was not significantly impacted. It is important to appreciate that reduced mRNA expression does not necessarily lead to reduced expression of the biologically active protein. Indeed, previous studies report that gene expression is more sensitive to external stimuli than its protein counterparts [38], and suggest that changes in gene expression are not necessarily mirrored by changes in protein expression $[39,40]$.

Discordance between gene and protein expression in Mmtv-Pymt mammary tumours may be due to the fluctuations in circulating hormones during the ovarian cycle, and the relative effect of hormonal stimulation on gene versus protein expression. We suggest that gene and protein expression are not directly comparable, and that the effects of ovarian hormones are likely more pronounced on gene expression-and by extension gene expression-based algorithms-compared to traditional protein-based methods. While it is believed that gene expression-based algorithms offer improved treatment decision-making capabilities compared to protein-based methods, the increased sensitivity of gene expression to hormonal stimulation cautions against the adoption of gene-based algorithms for guiding treatment decisions for premenopausal breast cancer patients.

\section{Conclusion}

Ovarian cycle stage in naturally cycling Mmtv-Pymt mice significantly affects the 21-gene signature in mammary tumours. Tumours collected from mice at diestrus exhibit a significant increase in Proliferation- and HER2group gene expression, and increase in 21-gene experimental recurrence scores. For premenopausal women, the menstrual cycle stage the time of tissue collection may affect the Oncotype DX 21-gene Recurrence Score. However, whether Oncotype DX Recurrence Scores in women are similarly affected by menstrual cycle stage is not yet known. To address this question and ensure young breast cancer patients receive optimal treatment 
advice, future prospective studies using breast cancer samples from premenopausal women with known cycle stage are required.

\section{Abbreviations}

ER: Estrogen receptor; HER2: Human epidermal growth factor receptor; RS: 21-gene experimental recurrence score; CDNA: Complementary DNA (CDNA); ACTB: Actin Beta; BAG1: BCL2-Associated Athanogene; BCL2: B-Cell CLL/Lymphoma 2; BIRC5: Baculoviral IAP Repeat-Containing 5 (Survivin); CCNB1: Cyclin B1; CD68: CD68 Molecule; CSTV: Cathepsin V; ERBB2: Erb-B2 Receptor Tyrosine Kinase 2; ESR1: Estrogen Receptor gene; GADP H: Glyceraldehyde-3-Phosphate Dehydrogenase; GRB7: Growth Factor Receptor-Bound Protein 7: GSTM1: Glutathione S-Transferase Mu 1: GUSB: Glucuronidase Beta; MKI67: Marker of Proliferation Ki-67; MMP11: Matrix Metallopeptidase 11 (Stromelysin 3); MYBL2: Myb Proto-Oncogene Like 2; PGR: Progesterone Receptor; RPLPO: Ribosomal Protein Lateral Stalk Subunit PO; SCUBE2: Signal Peptide, Cub Domain and Egf Like Domain Containing 2; STK15: Aurora Kinase A; TFRC: Transferrin Receptor

\section{Supplementary Information}

The online version contains supplementary material available at https://doi. org/10.1186/s12885-021-08496-y.

\section{Additional file 1}

\section{Acknowledgements}

A portion of this data was presented as an abstract at the 42nd San Antonio Breast Cancer Symposium; 10-14 December, 2019; San Antonio, Texas, USA, published in Bernhardt et al., Menstrual cycling critically affects the Oncotype DX 21-gene signature: implications for predictive biomarker assays in premenopausal women. Cancer Research Abstract P1-10-12 [41].

\section{Authors' contributions}

Conception and design of the study was conducted by SMB, PD, DJG, DW, ART, TJP, WVI. Animal studies were conducted by SMB and DJG, with histopathological analysis conducted by LW. T-SNE analysis was performed by LMM. Analysis and interpretation of data was conducted by SMB and WVI. The draft of the manuscript was written by SMB, with all authors providing intellectual input into the final manuscript. The author(s) read and approved the final manuscript.

\section{Funding}

This research was funded by The Hospital Research Foundation and The Queen Elizabeth Hospital Haem/Onc Scheme A. WVI is The Hospital Research Foundation Associate Professor of Breast Cancer Research. SMB is a PhD candidate at the University of Adelaide and funded through a Divisional Award. PD, DJG, LW, LMM, and WVI are University of Adelaide employees. DW, ART and TJP are SA Health employees.

\section{Availability of data and materials}

The datasets used and/or analysed during the current study are available from the corresponding author on reasonable request.

\section{Declarations}

\section{Ethics approval and consent to participate}

Animal experiments were approved by the University of Adelaide Animal Ethics Committee and were conducted in accordance with the Australian Code of Practice for the Care and Use of Animals for Scientific Purposes.

\section{Consent for publication}

Not applicable.

\section{Competing interests}

The authors declare that they have no competing interests.

\section{Author details}

'Discipline of Surgery, Adelaide Medical School, University of Adelaide, The Queen Elizabeth Hospital, Adelaide, 28 Woodville Rd, Woodville 5011,
Australia. ${ }^{2}$ Robinson Research Institute, University of Adelaide, Adelaide, Australia. ${ }^{3}$ School of Animal and Veterinary Sciences, University of Adelaide, Adelaide, SA, Australia. ${ }^{4}$ Adelaide Medical School, University of Adelaide, Adelaide, Australia. ${ }^{5}$ Department of Medical Oncology, The Queen Elizabeth Hospital, Adelaide, SA, Australia.

Received: 10 December 2020 Accepted: 14 June 2021

Published online: 26 June 2021

\section{References}

1. Coates AS, Winer EP, Goldhirsch A, Gelber RD, Gnant M, Piccart-Gebhart M, et al. Tailoring therapies-improving the management of early breast cancer: St Gallen international expert consensus on the primary therapy of Early Breast Cancer 2015. Ann Oncol. 2015;26(8):1533-46. https://doi.org/10.1 093/annonc/mdv221.

2. Harris LN, Ismaila N, McShane LM, Andre F, Collyar DE, Gonzalez-Angulo AM, et al. Use of biomarkers to guide decisions on adjuvant systemic therapy for women with Early-stage invasive Breast Cancer: American Society of Clinical Oncology clinical practice guideline. J Clin Oncol. 2016;34(10):1134-50. https://doi.org/10.1200/JCO.2015.65.2289.

3. Senkus E, Kyriakides S, Ohno S, Penault-Llorca F, Poortmans P, Rutgers E, et al. Primary breast cancer: ESMO clinical practice guidelines for diagnosis, treatment and follow-up. Ann Oncol. 2015;26(Suppl 5):v8-30. https://doi. org/10.1093/annonc/mdv298.

4. NCCN. NCCN clinical Practice guidelines in oncology 2017 V3: Available from: https://www.nccn.org/professionals/physician_gls/pdf/breast.pdf.

5. Paik S, Shak S, Tang G, Kim C, Baker J, Cronin M, et al. A multigene assay to predict recurrence of tamoxifen-treated, node-negative breast cancer. $\mathrm{N}$ Engl J Med. 2004;351(27):2817-26. https://doi.org/10.1056/NEJMoa041588.

6. Sparano JA, Gray RJ, Makower DF, Pritchard KI, Albain KS, Hayes DF, et al. Prospective validation of a 21-gene expression assay in Breast Cancer. N Engl J Med. 2015;373(21):2005-14. https://doi.org/10.1056/NEJMoa1510764.

7. Paik S, Tang G, Shak S, Kim C, Baker J, Kim W, et al. Gene expression and benefit of chemotherapy in women with node-negative, estrogen receptorpositive breast cancer. J Clin Oncol. 2006;24(23):3726-34. https://doi.org/1 0.1200/JCO.2005.04.7985

8. Albain KS, Barlow WE, Shak S, Hortobagyi GN, Livingston RB, Yeh IT, et al. Prognostic and predictive value of the 21-gene recurrence score assay in postmenopausal women with node-positive, oestrogen-receptor-positive breast cancer on chemotherapy: a retrospective analysis of a randomised trial. Lancet Oncol. 2010;11(1):55-65. https://doi.org/10.1016/S1470-204 5(09)70314-6.

9. Sparano JA, Paik S. Development of the 21-gene assay and its application in clinical practice and clinical trials. J Clin Oncol. 2008;26(5):721-8. https://doi. org/10.1200/JCO.2007.15.1068.

10. Sparano JA, Gray RJ, Makower DF, Pritchard KI, Albain KS, Hayes DF, et al. Adjuvant chemotherapy guided by a 21-gene expression assay in Breast Cancer. N Engl J Med. 2018;379(2):111-21. https://doi.org/10.1056/NEJMoa1 804710.

11. Augustovski F, Soto N, Caporale J, Gonzalez L, Gibbons L, Ciapponi A. Decision-making impact on adjuvant chemotherapy allocation in early node-negative breast cancer with a 21-gene assay: systematic review and meta-analysis. Breast Cancer Res Treat. 2015;152(3):611-25. https://doi.org/1 0.1007/s10549-015-3483-3.

12. Bernhardt SM, Dasari P, Walsh D, Townsend AR, Price TJ, Ingman WW. Hormonal modulation of Breast Cancer gene expression: implications for intrinsic subtyping in premenopausal women. Front Oncol. 2016;6:241.

13. Bernhardt SM, Dasari P, Wrin J, Raymond W, Edwards S, Walsh D, et al. Discordance in 21-gene recurrence scores between paired breast cancer samples is inversely associated with patient age. Breast Cancer Res. 2020; 22(1). https://doi.org/10.1186/s13058-020-01327-1.

14. Horimoto Y, Arakawa A, Tanabe M, Kuroda K, Matsuoka J, Igari F, et al. Menstrual cycle could affect Ki67 expression in estrogen receptor-positive breast cancer patients. J Clin Pathol. 2015;68(10):825-9. https://doi.org/1 0.1136/jclinpath-2015-203085.

15. Gompel A, Martin A, Simon P, Schoevaert D, Plu-Bureau G, Hugol D, et al. Epidermal growth factor receptor and c-erbB-2 expression in normal breast tissue during the menstrual cycle. Breast Cancer Res Treat. 1996;38(2):22735. https://doi.org/10.1007/BF01806677.

16. Haynes BP, Viale G, Galimberti V, Rotmensz N, Gibelli B, A'Hern R, et al. Expression of key oestrogen-regulated genes differs substantially across the 
menstrual cycle in oestrogen receptor-positive primary breast cancer. Breast Cancer Res Treat. 2013;138(1):157-65. https://doi.org/10.1007/s10549013-2426-0.

17. Haynes BP, Ginsburg O, Gao Q, Folkerd E, Afentakis M, Buus R, et al. Menstrual cycle associated changes in hormone-related gene expression in oestrogen receptor positive breast cancer. NPJ Breast Cancer. 2019;5(1):42. https://doi.org/10.1038/s41523-019-0138-2.

18. Haynes BP, Viale G, Galimberti V, Rotmensz N, Gibelli B, Smith IE, et al. Differences in expression of proliferation-associated genes and RANKL across the menstrual cycle in estrogen receptor-positive primary breast cancer. Breast Cancer Res Treat. 2014;148(2):327-35. https://doi.org/10.1007/ s10549-014-3181-6.

19. Need EF, Selth LA, Trotta AP, Leach DA, Giorgio L, O'Loughlin MA, et al. The unique transcriptional response produced by concurrent estrogen and progesterone treatment in breast cancer cells results in upregulation of growth factor pathways and switching from a luminal a to a basal-like subtype. BMC Cancer. 2015;15(1):791. https://doi.org/10.1186/s12885-015-1 819-3.

20. Bernhardt SM, Dasari P, Walsh D, Raymond W, Townsend AR, Price TJ, et al. The menstrual cycle is an under-appreciated factor in premenopausal breast cancer diagnosis and treatment. Curr Opin Endocr Metabol Res. 2020.

21. Lin EY, Jones JG, Li P, Zhu L, Whitney KD, Muller WJ, et al. Progression to malignancy in the polyoma middle $T$ oncoprotein mouse breast cancer model provides a reliable model for human diseases. Am J Pathol. 2003; 163(5):2113-26. https://doi.org/10.1016/S0002-9440(10)63568-7.

22. Asghar Butt S, Sogaard LV, Ardenkjaer-Larsen JH, Lauritzen MH, Engelholm $\mathrm{LH}$, Paulson $\mathrm{OB}$, et al. Monitoring mammary tumor progression and effect of tamoxifen treatment in MMTV-PymT using MRI and magnetic resonance spectroscopy with hyperpolarized [1-13C]pyruvate. Magn Reson Med. 2015; 73(1):51-8. https://doi.org/10.1002/mrm.25095.

23. Li J, Karaplis AC, Huang DC, Siegel PM, Camirand A, Yang XF, et al. PTHrP drives breast tumor initiation, progression, and metastasis in mice and is a potential therapy target. J Clin Invest. 2011;121(12):4655-69. https://doi. org/10.1172/JCI46134

24. Lin $\mathrm{EY}$, Nguyen $\mathrm{AV}$, Russell $\mathrm{RG}$, Pollard JW. Colony-stimulating factor 1 promotes progression of mammary tumors to malignancy. J Exp Med. 2001; 193(6):727-40. https://doi.org/10.1084/jem.193.6.727.

25. McLemore LE, Janakiram M, Albanese J, Shapiro N, Lo Y, Zang X, et al. An Immunoscore using PD-L1, CD68, and tumor-infiltrating lymphocytes (TILs) to predict response to neoadjuvant chemotherapy in invasive Breast Cancer. Appl Immunohistochem Mol Morphol. 2018;26(9):611-9. https://doi. org/10.1097/PAl.0000000000000485

26. Zhao X, Qu J, Sun Y, Wang J, Liu X, Wang F, et al. Prognostic significance of tumor-associated macrophages in breast cancer: a meta-analysis of the literature. Oncotarget. 2017;8(18):30576-86. https://doi.org/10.18632/oncota rget.15736.

27. Fata JE, Chaudhary V, Khokha R. Cellular turnover in the mammary gland is correlated with systemic levels of progesterone and not 17beta-estradiol during the estrous cycle. Biol Reprod. 2001;65(3):680-8. https://doi.org/10.1 095/biolreprod65.3.680

28. Dasari P, Sharkey DJ, Noordin E, Glynn DJ, Hodson LJ, Chin PY, et al. Hormonal regulation of the cytokine microenvironment in the mammary gland. J Reprod Immunol. 2014;106:58-66. https://doi.org/10.1016/j.jri.2014 07.002.

29. Allen E. The oestrous cycle in the mouse. Am J Anat. 1922;30(3):297-371. https://doi.org/10.1002/aja.1000300303.

30. van der Maaten LJP. HGE. Visualizing Data using t-SNE. J Mach Learn Res. 2008;9:2579-605.

31. Harvey JM, Clark GM, Osborne CK, Allred DC. Estrogen receptor status by immunohistochemistry is superior to the ligand-binding assay for predicting response to adjuvant endocrine therapy in breast cancer. J Clin Oncol. 1999; 17(5):1474-81. https://doi.org/10.1200/JCO.1999.17.5.1474

32. Viale G, Regan MM, Maiorano E, Mastropasqua MG, Golouh R, Perin T, et al. Chemoendocrine compared with endocrine adjuvant therapies for nodenegative breast cancer: predictive value of centrally reviewed expression of estrogen and progesterone receptors--international Breast Cancer study group. J Clin Oncol. 2008;26(9):1404-10. https://doi.org/10.1200/JCO.2007.10. 6393.

33. Early Breast Cancer Trialists' Collaborative G, Davies C, Godwin J, Gray R, Clarke M, Cutter D, et al. Relevance of breast cancer hormone receptors and other factors to the efficacy of adjuvant tamoxifen: patient-level metaanalysis of randomised trials. Lancet. 2011;378(9793):771-84.

34. Hodson LJ, Chua AC, Evdokiou A, Robertson SA, Ingman WV. Macrophage phenotype in the mammary gland fluctuates over the course of the estrous cycle and is regulated by ovarian steroid hormones. Biol Reprod. 2013;89(3): 65. https://doi.org/10.1095/biolreprod.113.109561.

35. Chua AC, Hodson L, Moldenhauer LM, Robertson SA, Ingman W. Dual roles for macrophages in ovarian cycle-associated development and remodelling of the mammary gland epithelium. Development. 2010;137(24): 4229-38. https://doi.org/10.1242/dev.059261.

36. Cohen PE, Zhu L, Pollard JW. Absence of colony stimulating factor-1 in osteopetrotic (csfmop/csfmop) mice disrupts estrous cycles and ovulation. Biol Reprod. 1997;56(1):110-8. https://doi.org/10.1095/biolreprod56.1.110

37. Going JJ, Anderson TJ, Battersby S, MacIntyre CC. Proliferative and secretory activity in human breast during natural and artificial menstrual cycles. Am J Pathol. 1988;130(1):193-204.

38. Schwanhausser B, Busse D, Li N, Dittmar G, Schuchhardt J, Wolf J, et al. Global quantification of mammalian gene expression control. Nature. 2011; 473(7347):337-42. https://doi.org/10.1038/nature10098.

39. Koussounadis A, Langdon SP, Um IH, Harrison DJ, Smith VA. Relationship between differentially expressed mRNA and mRNA-protein correlations in a xenograft model system. Sci Rep. 2015;5(1):10775. https://doi.org/10.1038/ srep10775.

40. Vogel C, Marcotte EM. Insights into the regulation of protein abundance from proteomic and transcriptomic analyses. Nat Rev Genet. 2012;13(4):22732. https://doi.org/10.1038/nrg3185.

41. Bernhardt SM, Dasari P, Glynn DJ, Woolford L, Raymond W, Moldenhauer LM, et al. Menstrual cycling critically affects the Oncotype DX 21-gene signature: implications for predictive biomarker assays in premenopausal women. San Antonio Breast Cancer Symposium 2019 Abstract P1-10-12 https:/www.abstractsonlinecom/pp8/\#!/7946/presentation/463

\section{Publisher's Note}

Springer Nature remains neutral with regard to jurisdictional claims in published maps and institutional affiliations.

\section{Ready to submit your research? Choose BMC and benefit from:}

- fast, convenient online submission

- thorough peer review by experienced researchers in your field

- rapid publication on acceptance

- support for research data, including large and complex data types

- gold Open Access which fosters wider collaboration and increased citations

- maximum visibility for your research: over $100 \mathrm{M}$ website views per year

At $\mathrm{BMC}$, research is always in progress.

Learn more biomedcentral.com/submissions 